\section{The impact of no-show in the public health service.}

\section{Valeria Campos Cannobbio. ${ }^{1}$}

It is well-known that over $85 \%$ of Chileans are affiliated with the public health service. The great demand for care at all levels, the shortage of medical specialists, the long waiting lists for inter-consultations, outpatient care and lack of operating rooms are also well-known. In general, there is a huge need for health care in all its areas and levels.

In spite of this high demand, a significant number of no-shows or nonattendance and treatment dropouts appear almost paradoxically, both in primary and secondary care (Salinas et al., 2014; Oliva et al., 2018).

Without going further, according to what was reported by Salinas et al. (2014), there is a $16.5 \%$ of absences to medical specialties in Chile, which is equivalent to approximately 28 million dollars lost per year, considering only the professional's fee. Another example is observed by Oliva et al. (2018), regarding the attendance to the dental GES (Garantías Explícitas en Salud Explicit Healthcare Guarantees) for pregnant women in a CESFAM (Centro de Salud Familiar - Family Healthcare Center), where $65.2 \%$ presented at least one no-show, specifically translating to 1 month of a dental box without giving attention to its users.

Although there have been studies quantifying these no-shows, few of them seek their causes. So far in Chile, socioeconomic factors would have greater influence in no-show than environmental factors, such as climate or distance to reference centers (Salinas et al., 2014). However, localized studies at a more individualized level are needed, because each region has its own geographical, socio-economic and cultural characteristics. In addition, we must not forget to complement these studies with qualitative approaches, because they allow to explore intrinsic and extrinsic aspects of the phenomenon in depth, and to value the importance of recognizing the heterogeneity of the users to attend their medical appointments.

According to my work experience in secondary healthcare level, many of the no-shows are due to the fact that patients do not know that they have a consultation appointment (since the contact telephone number was changed and there was no way to notify the patient), others because, as the appointment is sometimes requested two months in advance, people forget it or have another appointment. Another situation that I observed is that many of the first consultation patients (especially those from rural areas or away from the Hospital) arrived 40 minutes late, because they went astray inside the establishment, without knowing where their appointment was, thus losing it.

We must not forget that the resources of the Ministry of Health are scarce, every year the financial deficit of the Chilean public health increases, and that 2018's deficit exceeded 1,153 million dollars. Although the cause of
INT J MED SURG SCI

Affiliations: ${ }^{1}$ Universidad de Concepción School of Dentistry, Chile.

Corresponding author: Dra. Valeria Campos Cannobbio. Roosevelt 1550, Concepción, Chile. Phone: +56987690058.

Email: valeriacamposcannobbio@gmail.com.

Conflict of interests: None.

Acknowledgements: None.

doi: $10.32457 /$ ijmss.2018.023.

Campos Cannobbio V. The impact of no-show in the public health service. Int J Med Surg Sci. 2018; 5(3): 93-94. doi: $10.32457 / \mathrm{ijmss} .2018 .023$. 
this deficit is not due mainly to the no-show, this problem has not yet been resolved and it does affect the functioning of the services provided.

No-show is a problem that not only has individual consequences for not recovering the patient's health, often aggravating and increasing the cost of treatment, but also for the health system, resulting in less access to health services for the rest of the population, the people who need it.

\section{REFERENCES}

Salinas EA, De la Cruz R, Bastías G. Inasistencia de pacientes a consultas médicas de especialistas y su relación con indicadores ambientales y socioeconómicos regionales en el sistema de salud público de Chile. Medwave. 2014; 14(9): e6023.

Oliva J, Olivares M, Cartes-Velásquez R, Luengo L, Campos V. Use of the Explicit Health Guarantee of Oral Health Care for Pregnant Women at a Family Health Center, Concepción, Chile, 2014-2015. Dent med probl. 2018; 55(2):179-183. 